\title{
Péter Szatmári - György Suha \\ International Development Policy Structures for Cooperation in Science, Technology and Education in Hungary
}

\section{Summary}

In the context of Hungarian development policy, scientific and educational cooperation has a key role. The primary aim of this paper is to give an overview of the significant elements of the current international development cooperation and international humanitarian activities in Hungary. Secondly, it analyses, in a dimensional approach, the opportunities of policy and organisational structures and funding mechanisms for science, technology and innovation in developing countries. This article recommends more subtle ways of reforming political decisions that could support innovation with a deeper insight into some aspects of Hungarian "best practices". Finally, it touches upon issues of tertiary education including the identification of funding instruments and interactions between the private sector and government actors.

Journal of Economic Literature (JEL) codes: F35, F53, G18, H52, I28

Keywords: development, research, tertiary education, funding mechanism, Hungary

Dr Péter Szatmári, CSc, Rector, King Sigismund University (szatmari@uni-zsigmond.hu); Dr György SuHA, Ambassador, Ministry of Foreign Affairs and Trade (tbk@mfa.gov.hu). 
International development cooperation and international humanitarian activities form an important part of Hungary's international relations and as policies developed in line with Hungary's commitment in the international donor community are key elements of Hungary's role in addressing global challenges. According to the relevant Hungarian law in force, ${ }^{1}$ under the management of the Minister of State for Security Policy and International Cooperation of the Ministry of Foreign Affairs and Trade and the Deputy State Secretary for International Cooperation, the Department for International Development and Humanitarian Assistance is responsible for developing a policy for the International Development Cooperation and International Humanitarian Assistance, for its coordination by the Government, and for its implementation. ${ }^{2}$

Hungary's 2016 annual summary statistics about spending on official development assistance pointed out that last year, similarly to previous years, multilateral development cooperation prevailed, primarily due to the ratio of mandatory contributions to the EU, voluntary contributions to various EU Funds and support for international organisations. In terms of bilateral International Development programmes and projects, the problem of resources with a low level of funding reappeared. Within the OECD, the Development Assistance Committee (DAC) was founded in 1960. Hungary joined to the OECD in 1996 and since its accession to the EU, it has had an observer status in the OECD DAC as an EU Member State. As a result of the accession procedure, launched in 2016 and taking several months, Hungary became the $30^{\text {th }}$ full member of the DAC on 6 December $2016 .{ }^{3}$ As a member of the Committee, Hungary became part of a global process that aims at coordinating Development Policy all over the world, and deals with the coordinated implementation of the UN Development Sustainable Goals in the long run, as crises can only be handled effectively if a global approach is adopted and Member States cooperate. The Sustainable Development Framework, establishing directions for development after 2015, called Agenda 2030, was adopted by consensus on 25-27 September 2015, at the UN Development Summit, by the Heads of State and Government of the UN Member States with Hungary as a participant. The Framework sets 17 goals and 169 partial goals for the period between 2016 and 2030, and replaces the Millennium Development Goals (MDGs) adopted in 2000. ${ }^{4}$ Hungary had a pivotal role in establishing the Sustainable Development Goals (SDGs), since Hungary co-chaired the UN Open Working Group (OWG) commissioned to make a proposal for the goals with Kenya for one and a half years. In terms of adopting the framework, it was emphasised that international peace and security and sustainable development are inseparable, and thus the causes triggering conflicts can only be eliminated through sustainable development. Moreover, the Agenda includes a target system and sub-system to achieve the dual aim of poverty reduction and sustainable development in a balanced manner. Simultaneously with intergovernmental negotiations aiming at the establishment of the Sustainable Development Framework, preparations were going on for the 3rd Funding for Development Conference of the UN held between 13 and 16 July 2015 in Addis Ababa. The final document of the Conference, the Addis Ababa Action 
Agenda (AAAA) forms an integral part of the Sustainable Development Framework 2030, thus providing its implementation. The Sustainable Development Framework and the Paris Agreement adopted at the 21st Conference (COP21) of the parties of the United Nations Framework Convention on Climate Change (UNFCCC) are interconnected in many ways. The elements of transformation included in the Agenda 2030 have an effect on the implementation of the decisions made at the Climate Summit, while the decision about the legally binding climate agreement also affects all the goals of the Framework.

Migratory pressure is still one of the greatest challenges affecting Europe. The International Development Cooperation has a key role in handling factors that trigger migration locally, that is, in providing assistance through international cooperation to ensure living conditions appropriate for hundreds of millions of people so that they are not compelled to leave their home countries. The main goal of the UN Sustainable Development Framework adopted in 2015 (Agenda 2030), including the Sustainable Development Goals (SDGs), is that people can live in peace and security, under balanced and sustainable conditions in every state of the world within 15 years. Besides the "human sectors", the International Development scheme also has a great potential in terms of the economy. Development activities also contribute to improving the international opinion about a particular country and to enabling the economic actors to pursue their interests in the medium to long term. While migration and asylum were not among the priorities of development and foreign policy instruments under the EU budget, due to the mass waves of migrants and asylum seekers coming to Europe, they were integrated horizontally into most of the sub-programmes, which in turn resulted in the reallocation of resources. The Commission started to use the funds, in an ever increasing ratio, for supporting the resettlement and assimilation of migrants and refugees primarily in countries the neighbouring the states affected by conflicts, and wherever the conditions allowed, also for providing assistance to them to return to their homeland. The Commission set the overall objective of providing better living conditions for forced migrants and refugees also during the transitional period spent in refugee camps and host communities. Thus, the EU paid greater attention to remedying the consequences of mass displacements in addition to handling the causes that trigger migration (e.g. deep poverty, unstable political and economic systems, harsh security conditions, etc.). However, this did not mean a complete change of focus: it was rather a more focused approach in handling consequences, which - in terms of handling causes - had been established by the beginning of 2016, mainly as a result of establishing Trust Funds ${ }^{5}$. Making payments to the extra-budgetary European Development Fund, which serves the development of the African, Caribbean and Pacific Group of States (ACP) as part of the Cotonou Agreement, is Hungary's obligation arising from EU membership. At the moment the scheduling and allocation of funds is under way for the 11st $\operatorname{EDF}^{6}$ (2014-2020). The overall budget of the 10th EDF is EUR 22.682 billion, out of which Hungary has to pay EUR 125 million based on its quota $(0.55 \%) .{ }^{7}$ The funds can only be used in specific sectors as set out in particular country strategies (in general: environmental 
protection, water management, energy, agriculture, food industry, health care industry, construction, education and culture, building capacities, human rights, migration and supporting democracies).

Hungary has been a member state in the Organisation for Economic Co-operation and Development (OECD) since 1996. DAC plays a leading role plays a pivotal role in this procedure and in reducing poverty. DAC urges and assists its member states in establishing a comprehensive Development Policy and in coordinating their particular policies with Development Policy, and once in every four years it makes a comprehensive evaluation of the International Humanitarian Assistance and Development Policy of each member state. Hungary takes part in the high level and executive meetings of DAC, as well as in its monthly formal sessions and in the work of particular committees. As regards the reform of ODA, the integration of new, innovative forms of funding into development funding performed in the various working groups of the OECD in 2016 with the main focus on soft loans eligible as ODAs, the administration of development activities in the private sector, and the just recognition of the amount of energy invested by the donors besides the profit of recipient countries. In terms of bilateral scholarships and contributions for developing countries in 2016, 103 students from developing countries participated in the Stipendium Hungaricum programme funded by the Ministry of Human Capacities and coordinated by the Tempus Public Foundation. The scholarship programme, which has become well-known again after several decades, is especially important. It aims to improve Hungary's "international visibility", presenting our national values in a global context. The aim of the educational policy programme is to foster the internationalisation and improve the quality of Hungarian tertiary education, to strengthen the international relations of the Hungarian academic elite, to increase the cultural diversity of tertiary education institutions and to promote the competitive Hungarian tertiary education all over the world. The economic and foreign policy objective of the programme is to lay the foundations of the personal and professional attachment of students graduated in Hungary, thus potentially enhancing the understanding of Hungarian peculiarities and interests among the elite of their home countries, and establishing the social capital necessary for developing Hungarian economic relations and fostering its aspirations for a market entry. It is not negligible that the presence of international students has a positive impact on the economic development of a particular city or region. In addition, the programme contributes to the promotion of the Hungarian language, as some students start their university studies in Hungarian, following a preparatory training. In the multilateral context, the university-level agricultural programme in Hungary for fellows from developing countries based on the agreement between the Government of Hungary and UN FAO, which continues the practice of previous years, falls into this category. The contribution made by the Ministry of Agriculture to the UN FAO scholarship enabled 34 countries to participate. The Regional Educational Centre of the Hungarian Competition Authority organised five seminars on competition law in 2016, as part of its annual programme for the competition authorities of its primary target countries out of which three events were held in Budapest, one in the Russian 
Federation and another in Serbia. Within the framework of its bilateral agreements, the Hungarian Academy of Sciences provides financial assistance for the mobility costs of joint research projects and gives mobility support for individuals who wish to travel with research purposes. The subsidised projects mainly last for 2-3 years. The Hungarian Academy of Sciences provided financial support for 10 developing countries in 2016. Moldova held the presidency of the Police Cooperation Convention for Southeast Europe (PCC SEE) in the first half of 2016. The Moldavian party, due to training programmes previously organised at the International Training Centre of the Hungarian Ministry of Interior and building on the positive experiences during last year's Hungarian presidency, asked the Hungarian Ministry of Interior and the PCC SEE Secretariat to organise the Moldavian Presidency's training programme ${ }^{8}$ in Hungary. The Hungarian party did not only provide logistics support and assistance for the organisation, but an instructor of the Faculty of Military Sciences and Officer Training of the National University of Public Service also developed the curriculum of the training programme and moderated the training together with the PCC SEE lecturers. 16 military education specialists from ten PCC SEE countries participated in the training, and they found it professional and highly organised. Similarly, professional cooperation based on special knowledge transfer was initiated by the Secretariat of the Police Cooperation Convention for Southeast Europe (PCC SEE). The target group of the training was the pool of military experts with multiple years of experience in the field of the document security of PCC SEE member states. ${ }^{9}$ The aim of the professional forum was to provide an opportunity for regional professionals to share their experiences about false and forged Iraqi documents, to review trends and best practices in the field of document security and to strengthen the professional network in the area of documents within the PCC SEE. In addition to the British, German, Belgian and Swiss experts, the Pest County Policy Headquarters, the Ministry of Foreign Affairs and Trade, the Hungarian Special Service for National Security and the National University of Public Service also sent lecturers to the workshop. The curriculum of the training was developed by the professionals of the Hungarian National Police Headquarters, the International Training Centre of the Hungarian Ministry of the Interior and the National University of Public Service in collaboration with the representatives of the Secretariat. Since 2012, Hungary has been a member of the Delhi-based Global Development Network. It is an international network of researchers in Development Studies that focuses on the development of the Third World. The organisation excels other international research institutions and networks by organising its annual conferences presenting new research results. ${ }^{10}$

Recently, Hungarian diplomacy has also sought to enhance cooperation between the various disciplines of the Hungarian Academy of Sciences especially in the areas of Sustainable Development, Climate Impact, Healthcare and Agricultural Sciences and the scientific and educational professionals of countries entitled to ODAs. Bridging the gap in academic knowledge and education in underdeveloped countries is of key importance in development. In October 2016, the Committee for International and Development Studies of the Hungarian Academy of Sciences received the delega- 
tion in Hungary for the preliminary investigation before the Committee's accession to DAC, and informed them about the cooperation between the Ministry and the academia. However, the results of these efforts also depend on the commitment of the parties. This partnership assumes governmental awareness and an appropriate national legal environment.

\section{Countries ShOuld COMMit TO Invest in R\&D}

Experience leaves no doubt that innovation (developing and commercially and/or socially exploiting new products, processes, services, infrastructure, etc.) is vital for the success of companies (at the microeconomic level) and economies and to increase individual freedoms, the quality of life and societal well-being, at the social level (Sener and Saridogan, 2011). OECD countries show that higher per employee and more intense technology diffusion correlate strongly with total factor productivity. The impact of innovations ${ }^{11}$ in communication, mobility and e.g. healthcare on the quality of life is unmistakable. Innovation is the result of technological development in combination with organisational changes, new management methods, marketing concepts, financial techniques or policy approaches. All these increasingly rely on scientific research done in natural, engineering and medical sciences, and at present more than in the past, to a major extent in social sciences and the humanities. Former developing countries in East and South-East Asia, ${ }^{12}$ Latin-America and also South-Africa ${ }^{13}$ demonstrate that this is the way ahead. Companies do invest in research and development, which they would not do in the absence of good economic reasons, and that is why in almost all OECD countries business funding R\&D has increased ${ }^{14}$ considerably. But firms are withdrawing from longer-term research, while patents reveal that they are based increasingly on academic research findings (citation in patents of academic publications). So here is an important reason why government investments are necessary for maintaining the overall R\&D enterprise. More generally, there are three compelling arguments. The first one focuses on improving the quality, productivity, cost-effectiveness and accessibility of a variety of services, ${ }^{15}$ infrastructure and policies which fall within the - full or partial, direct or indirect - responsibility of the government. Secondly, while basic research does not exclusively serve public good (in other words, others can also use it without diminishing the value for its producers and other firms cannot be prevented from using it), firms will obviously not invest in the entire research they eventually benefit from. Governments have to step and have always stepped in through funding research at universities and institutes of basic science. Thirdly, a considerable amount of knowledge is "tacit" and embodied in persons, procedures and organisations. Using published knowledge requires extensive and expensive learning processes; and capabilities (people, equipment, etc.) are necessary to appreciate and assimilate ("absorb") results from elsewhere. This leads to the modern rationale for investment in public basic research, which creates technological opportunities; increases technological diversity by providing a source of new interactions, networks and technological options, whereas firms tend to exploit the variety 
included in the existing technological path; and it is also a source of skills, required to translate knowledge into practice; an enhanced ability to solve complex technological problems; and the "entry ticket" to the world's stock of knowledge. Countries that have been able to benefit most from science and technology have systematically built up ways and means to carry out research and development and support firms, government agencies and other organisations in society at large in applying research findings, whether domestically or abroad. Several characteristics are shared, and developed countries, emerging economies and some developing countries do not differ considerably in this regard.

\section{ORGANISATION AND FUNDING SYSTEMS FOR SCIENCE}

In many developing countries establishing a national body with responsibility for science and technology was part of the initial institutional framework. ${ }^{16}$ They had, and sometimes still have, a series of responsibilities: defining policies for science and technology, coordinating science and technology and funding R\&D are often included, but also supervising or managing research institutes. They may also attend to the registration of ongoing research, assume responsibility for compliance with international provisions (biodiversity and ethics for example), propose legislation for intellectual property, and occasionally even run a national patent office. A key lesson successful countries have learnt is the need to differentiate between several of these functions and to articulate them in separate organisations, some of them within the government structure, some at arm's length or completely independently. In several countries a new type of body has emerged over the past decade or so as an expression of the importance of science and technology, and education, in the social and economic development of a country. The increasing focus on innovation as the mechanism through which the impact of science and technology is often realized, and the awareness that an international, global perspective must be developed only add to the reasons to create such a Research and Innovation Council (which is the name of a successful example in Finland ${ }^{17}$ ). The essence is that the government, the industry, research organisations, universities and vocational training institutions agree on and commit to a medium- or long-term vision and strategy of economic and social development. To this end, the government creates a high-level body combining key stakeholders from the government, the private sector and other institutions. Developing and agreeing on the key components of a strategy for economic development; committing to working together, coordinating activities, and mobilising the members' respective constituencies; defining systematic action plans (for example as regards incentives to improve the business environment and entrepreneurship; human resources development; technology, knowledge and innovation; the information infrastructure; communicating with society at large) and monitoring and measuring progress would

be the key roles of such a council. It would not take over formal responsibilities but if stakeholders indeed commit to a direction and to work together it may be a powerful informal instance of coordinating across the public and private sector. 


\section{ROLE OF A VITAL BUSINESS SEGTOR}

The most obvious standpoint (Golob et al., 2002) is that the business (entrepreneurial) sector usually does not undertake considerable research. Indeed, historical experience shows that with increase in the overall R\&D efforts in a country, the financial share of enterprises in the total amount of R\&D also increases. ${ }^{18}$ The Gross R\&D Expenditure measured as a percentage of Gross Domestic Product (GERD/GDP), which in quite a few countries is now close to or upwards of $3 \%$, is financed at a rate exceeding two-thirds by private enterprises. In the period between 2000 and 2015, the GERD share in Hungary rose by a total of 0.59 percentage points. It reached its peak in 2013, when the gross research and development-related expenditure made 1.39 percent of Hungary's GDP. In 2015, this ratio was 1.38 percent, considerably lower than in Austria but higher than in Italy. To the extent that proper economic, social and legal conditions result in expanding and strengthening the sector of private enterprises, one may also expect private $\mathrm{R} \& \mathrm{D}$ efforts to grow. ${ }^{19}$ One very effective way is to support companies in employing scientists, engineers and advanced technicians. In many countries schemes are in place to subsidise the wage costs at a decreasing rate, say from $75 \%$ in the first year to $25 \%$ in the third one, and $0 \%$ thereafter. Companies often retain these persons subsequently. Financially supporting specific $\mathrm{R} \& \mathrm{D}$ or innovation projects in companies after an independent check on likely viability or collaborative projects between a company and a researcher at a university or public research centre is also proven to be effective. Technology adaptation and dissemination programmes with a group of companies or an industry branch, supported by a (public) national industrial research institute, are another example. Dissemination is indeed one of the fastest ways to increase the skills and productivity of companies on a wider scale..$^{20} \mathrm{It}$ is in the focus of attention in many emerging economies, and is increasingly discussed in developing nations. The key notion is that there is often a certain specialization of economic activity in a region, whatever the precise size. There is a virtuous circle of "proximity": companies, even outright competitors benefit from the same suppliers, from agreements and interaction with universities, polytechnics and technical colleges for focused training, from regional governments and banks creating optimal conditions, from joint public, public-private or even private R\&D programmes, and so on. Science or technology parks, or public industrial research institutes, with incubator and business development services to assist entrepreneurs in the initial stages of setting up and growing their company, are part of the game everywhere. And very directly, providing tax support, by allowing companies to deduct part of the salary costs of R\&D personnel, is found in general by economists to be an effective stimulus. All in all, developing a rich mix of measures and instruments to help increase skills levels, productivity and R\&D efforts of companies is a key policy area and challenge for governments in developing countries. There are numerous good examples, and countries moving fast, such as China and South Africa, have gone already quite some way (Haour and Zedtwitz, 2016). 
Péter Szatmári - György Suha: International Development Policy Structures for...

TERTIARY EDUCATION SEGTOR:

PUBLIC AND PRIVATE RESPONSIBILITIES

The university sector or, more generally, tertiary education deserves considerable attention. Many developing countries and emerging economies have seen the sector evolve in a particular way. Often one finds one, by now very large, national university which in the past drew most of the talent in the country, both as professors and as students. As student numbers began to grow new national and increasingly private universities were established (Tindemans, 2009). The (former) national university has often grown so large that concerns for decreasing quality are more than justified as funding has not matched the student numbers. Research was rather concentrated at the national university, also because in many cases this university had close links to one or two universities abroad. Private universities concentrate with few exceptions on areas such as business administration, finances, ICT or for example international relations. The mushrooming number of small universities ${ }^{21}$ has, however, brought a serious quality issue to the fore, making a considerably tighter accreditation system an absolute necessity. Sometimes, however, governments are still very restrictive in providing licenses to private universities or in other ways, sometimes unknowingly, raising obstacles. The result is that in those countries gross enrolment into tertiary education is at a very low level. Public financing is often non-transparent and rather more follows historical patterns than funding mechanisms that allocate the scarce public resources in the best possible way (McLendon, 2003). Moreover the national university or the few public ones rather deal with the ministry of finance than the ministry of (higher) education, creating a further hurdle towards a transparent and equitable system. In countries with a very strong academy of sciences the additional problem was and often still is that the development of a strong research capacity at universities was effectively choked. Establishing a more balanced system of tertiary education, which is much less focused on one or a few central universities is essential. There are very good reasons for differentiating between universities and professional institutions that offer shorter (one to two year) degree programmes or diplomas or longer (three to four year) professional degree programmes. Only a relatively limited number of universities should be encouraged or allowed to develop into or continue operation as research universities. The dilution of research funding is a threat all over the world and a serious issue, for example, in Europe, but much less so in the US. China clearly follows the US example. Providing high-quality undergraduate education is an important and valuable mission for a tertiary educational institution. A set of interlinked issues relate to the functioning of institutions of tertiary education. But governments need to create the majority of the conditions that provide incentives for the individual institutions to improve their management and operating methods. Universities need strong management, as the traditional academic procedures of appointing persons to key positions are not always well suited to modern requirements. The same applies to human resource management already mentioned in the context of staff development. Universities and other tertiary institutions need increased au- 
tonomy, including internal financial autonomy and flexibility in employment conditions. Those conditions, at least in public institutions, often resemble those of the civil service, and the recognition that these are not suitable has taken roots worldwide. Governments are increasingly granting autonomy in exchange for accountability. ${ }^{22}$ That is often combined with various forms of performance-based funding, discussed in greater detail in the next section. A link to national priorities is another element whether this is implemented through a financial mechanism or not. Governments may require universities to respect such priorities in ways they may freely choose but should report upon in their annual accounts or strategic plans.

\section{SUPPORTING INNOVATION：FUNDING INSTRUMENTS}

Developed countries, the most advanced countries and emerging economies do not only differ in the availability of funding, but also in the lack of a differentiated and transparent funding system for research and innovation. It may seem a technical matter, but it is not. Funding mechanisms play a crucial role in improving quality, managing researchers and institutes, ensuring both sustainable infrastructure for research and competition dynamics, and in providing incentives for cooperation between universities and companies. As an example, in quite a few developing countries experience is now being built up through a mechanism of providing funding on a competitive basis to excellent researchers and their teams, using (international) peer review as a selection procedure, funding coming from international partners in development.

In the first place, governments provide direct funding from their tertiary education budgets, mostly as institutional or core funding, to create the infrastructure for research. There are several ways in which this can be done. Even in developed countries this is still often strongly based on discretionary ways, described by some as arbitrary. But attempts are being made to base these core funding allocations on more or less detailed budgeting and on the funding of specific cost categories, governments or tertiary education funding agencies tasked by governments in some countries to replace governments in doing this, increasingly searching for formula-based lump sum contributions, and this implies that governments base their contribution on rational calculations ${ }^{23}$ whereas universities retain the full freedom to spend the money in ways they deem fit. Both past performance and agreed future targets may lie at the basis of such performance - or formula-based funding mechanisms. The second major contribution to university research also comes from the government, but through and independent "Research Council" (there may be more of them for different fields of science) and, to a minor extent, from an "Innovation Funding Agency". This funding is typically provided on a competitive basis, using (international) peer review as the selection mechanism. The ratio of what is often called the "first flow of funds" to university research and the "second flow of funds" varies widely. Some countries (with the US and the UK as key examples) rely heavily on the competitive mechanism, others place the emphasis on the core funding. Actually, this is a policy issue: continuity versus dynamics, as some would like to phrase the dilemma. How to promote 
concentration of research and thus differentiation of missions of tertiary educational institutions is a vexing problem that governments in most parts of the world face. With regard to tapping private resources, whether it is for stimulating companies to carry out more research or for attracting private donations to boost research in public institutions, governments need to consider which tax measures will effectively trigger individuals, private foundations or charities and enterprises. Competitive funding for research projects is a key as a complement to institutional funding. Nowadays almost all countries nowadays avail themselves of a mechanism to provide such funding. The National Science Foundation ${ }^{24}$ in the USA is a well-known example, but in the framework of modernizing research and research funding systems, many countries have set up "Research Councils" or National Funding Agencies with the main task to make research money available for the best researchers by transparently assessing proposals or past performance through peer review (often international) in competition. There is a good case for allowing them operate to a major extent in a "self-organising" mode, run by scientists, although governments should set a certain framework for such a National Funding Agency. The Russian Foundation for Basic Research ${ }^{25}$ and the National Natural Science Foundation of China ${ }^{26}$ have been successfully functioning for the past twenty years, but also the Uganda National Council for Science and Technol$\mathrm{ogy}^{27}$ now also provides competitive grants from government money with assistance from the World Bank. Even in France, a country which used to rely extensively on CNRS having its own research institutes and research units at French universities, the French Research Agency ${ }^{28}$ (AFR) now provides competitive funding. As the STI system evolves and extends, governments may wish to consider whether more research councils or funding agencies would better serve the different fields of science (Tindemans, 2009). As mentioned above, governments can do several things to encourage companies to increase skills, productivity and research efforts. How should one go about it? And what type of support measures is one to consider? Initially for reasons of efficiency and the lack of (human) resources one may well consider to making the same funding agency that on a competitive basis funds academically-oriented or strategic research also responsible for the support measures that target companies in the first place. But eventually, as the STI system matures, one usually finds a separate agency tasked with the promotion of research and innovation in companies. The reason is that proposals to get support from companies or involving companies often require some form of business plan, market assessment and a strong managerial approach. Assessing such proposals requires different skills from those who need to assess on a competitive basis research proposals. Governments are also considering the instruments they can use to introduce more differentiation, concentration and specialization, which as mentioned before are important policy challenges for the tertiary education system. This has led in several countries to competition between various institutions as a whole or departments rather than between individual scientists. Sometimes public and private partnerships are required in such competitions. The competition is not always complete. For example in China's case, the limited number of universities allowed to participate in the so-called "Project 985" were identified 
by the government, ${ }^{29}$ using academic performance as an important criteria. Another strategy governments may adopt, especially to increase concentration and also specialization, includes mergers between tertiary educational institutions. It is not an easy option to implement, and certainly not when part of the problem is the occasionally very high number of rather small private tertiary institutions. Yet governments should consider the use of accreditation to improve efficiency and quality by increasing the average size of universities and providers of professional training.

\section{CONSISTENT STI SYSTEM AS TOOL FOR DEVELOPMENT}

Closely linked to the system of funding science, technology and innovation (STI) and to the functioning of tertiary educational institutions and research institutes is the system of quality assessment. Theoretically sometimes a distinction is made between Quality Control (QC), which is the licensing or accrediting of institutions or programmes ex ante; Quality Assurance (QA), which relates to assessing ex post whether programmes (not institutions) have performed according to the set goals and promises; and quality promotion or fostering, which means the adoption of the attitude of making quality a key parameter in the management of an institution, of faculties, the provision of education and the conduct of research. Autonomy is increasingly provided in exchange for accountability and the latter often depends on reliable quality assurance mechanisms to be in place. One important component of such a system of quality assurance is a formal accreditation system for tertiary education. Many countries nowadays require that the individual programmes (an undergraduate or graduate programme in chemistry, for example) and/or institutions as a whole are accredited on a regular basis. Public funding (in the case of public institutions) or the operating license (in the case of private institutions) can be made dependent on a positive outcome, although in both cases some think that market information (in the form of outcomes of accreditation reports, in other words, naming and shaming) available for students automatically does the work without formal sanctions. Not all countries have a national system; some depend on professional bodies (for example, in engineering) to perform the accreditation. But the mechanism is basically the same: the institution (or department or programme management) is required to carry out a self-evaluation - retrospective and prospective - according to a strict protocol; an accreditation committee appointed by the accreditation body visits the site, and writes an accreditation report with recommendations or even requirements for improvements to be made before the accreditation body gives its verdict. Setting up a proper, transparent and unbiased accreditation system is one of the urgent challenges for governments in developing countries, and it is a very positive development that this is now happening on a significant scale. This is also an area offering quite some scope for regional and international cooperation to exchange views, to establish common protocols, to get international experts on board for national accreditation exercises, and eventually maybe to set up joint accreditation systems. On a global level one finds the International Network for Quality Assurance Agencies in Tertiary educa- 
tion, ${ }^{30}$ the INQAAHE with membership from all over world from developed countries, developing countries and emerging economies. The research staff is considerably less homogeneous in terms of quality assurance mechanisms. They are straightforward in the case of agencies providing competitive funding as the evaluation is the key element during selection and granting. But for the core or institutional funding component of research at universities or research institutes, practice still widely differs, or is completely absent. Yet, governments are increasingly of the view that public funding needs to be linked to regular performance evaluations. For this reason, an increasing number of governments appoint committees to evaluate research institutes in a way similar to the accreditation process in education: by self-evaluation, site visits and a verdict with or without direct financial or other implications (including the dismissal of the management). In other cases, governments only require that the institutions or umbrella organisations take the responsibility for such evaluations, and then report the findings to the government. The standard of measuring and evaluating the performance of a research organisation naturally depends on the nature of the institute. An institute for clinical research, an institute for industrial research and an institute for agricultural research that may use a considerable extension component, have different audiences and clients, require different evaluation criteria, and their clients must be strongly involved in assessing performance.

A marked difference between the universities and research institutes in developing countries and in developed nations is found in the area of information and communication technology support. Education, especially tertiary education, and research depend so heavily on support that closing the gap is impossible without adequate provisions. Computers, software tools, management information systems are needed in large numbers, and people need to be trained to use all these. In the past two decades, the establishment and building of a network that provides high-quality data communication services has become of paramount significance. In all developed countries and in many others dedicated national networks called NRENs are in place for the purpose of research and education. These are "knotted" together by continental and global links (very high-capacity cables, increasingly optical fibres). In many developing countries the local capacities are insufficient, national connectivity is poor, as is international connectivity. The other side of the coin is that costs are very high and reliability is low. There is no reason why that situation should be allowed to persist. With the new undersea cable along the African coast, the global coverage of the backbone system is virtually complete. What remains to be built are the national systems and their connection to the continental and global backbones.

\section{Notes}

1 Act XC of 2014 on International Development Cooperation and International Humanitarian Assistance was passed by the National Assembly during 15 December, 2014 session.

2 http://nefe.kormany.hu/act-xc-of-2014-on-international-development-cooperation-and-internationalhumanitarian-assistance-is-now-accessible.

3 www.oecd.org/hungary/hungary-joins-the-oecd-development-assistance-committee.htm. 


\section{Civic Review · Vol. 14, Special Issue, 2018}

4 The main difference between the two frameworks is that while MDGs focus only on the problems of developing countries, primarily on humanitarian assistance, the new goals also concern developed countries.

5 The Trust Fund on Financing for Development was established in May 2000, in order to support substantive preparations for the International Conference on Financing for Development (March 2002, Monterrey, Mexico) and the participation of developing countries in the Conference. The Trust Fund now seeks voluntary contributions, in order to support the preparation and organisation of the third International Conference on Financing for Development.

6 Financially, the Member States still make payments for the 10th EDF (2008-2013).

7 The overall allocation for the 11th EDF has increased to EUR 30.5 billion, and so has the quota for Hungary $(0.61 \%)$, thus Hungary's payment obligation has increased to EUR 187 million.

8 The training focused specifically on a "Train the Trainer" type of programme for developing and holding PCC SEE webinars.

9 Austria, Albania, Bosnia and Herzegovina, Bulgaria, Hungary, Macedonia, Moldova, Montenegro, Romania, Serbia, and Slovenia.

10 The large-scale conference on Development and Urbanisation was held in Budapest in 2012.

11 www.oecd.org/innovation/inno/50586251.pdf.

12 https://medium.com/@LetsTalkPayments/fintech-innovation-in-southeast-asia-f723945d5208.

13 www.worldbank.org/en/country/southafrica/publication/south-africa-economic-update-more-innovation-could-improve-productivity-create-jobs-and-reduce-poverty.

14 https://www.oecd.org/sti/outlook/e-outlook/stipolicyprofiles/competencestoinnovate/financingbusinessrdandinnovation.htm

15 Examples include defence, education, health, water, energy and food security, physical infrastructure, governance, social security, protection from crime, or regional and global obligations governments increasingly have (e.g. biodiversity or climate change).

16 Various names occur such as a national council for science and technology or a national or state commission for science and technology.

17 http://valtioneuvosto.fi/en/research-and-innovation-council.

18 https://data.worldbank.org/indicator/GB.XPD.RSDV.GD.ZS.

19 Yet, there are many things governments can do to promote this.

20 An approach that has attracted considerable interest concerns so-called industrial or economic clusters.

21 Having less than 5000 students.

22 This has several dimensions, but a system of quality assurance which provides transparent and comparative information on the quality of education, research and outreach activities (such as community services or technology transfer) that institutions of tertiary education carry out, is at the core.

23 E.g. the number of students and/or degrees granted when it comes to education, or on publications or $\mathrm{PhD}$ degrees in the case of research.

24 The National Science Foundation is a United States government agency that supports fundamental research and education in all the non-medical fields of science and engineering, www.nsf.gov.

25 www.rfbr.ru.

26 www.nsfc.gov.cn.

27 uncst.go.ug.

28 www.agence-nationale-recherche.fr.

29 The project was first announced by the CPC General secretary and Chinese President Jiang Zemin at the 100th anniversary of the foundation of Peking University, on May 4, 1998, to promote the development and reputation of the Chinese tertiary education system by the establishment of world-class universities in the 21st century and eponymous after the date of the announcement, May 1998, or 98/5, according to the Chinese date format.

30 The International Network for Quality Assurance Agencies in Tertiary education is a world-wide association of near 300 organisations active in the theory and practice of quality assurance in tertiary education, www.inqaahe.org. 
Péter Szatmári - György Suha: International Development Policy Structures for...

\section{REFERENCES}

Carbone, Maurizio (ed.) (2009): Policy Coherence and EU Development Policy. Routledge, New York.

CESifo (2015): National plans for science, technology and innovation policy. CESifo Group, Munich, www.cesifo-group.de/de/ifoHome/facts/DICE/Education-and-Innovation/Innovation/Innovation-Policies/ National-plans-STI/fileBinary/National-plans-STI.pdf (accessed 17 November 2017).

Golob, Peter; Farrell, Graham and Orchard, John E. (eds.) (2002): Crop Post-Harvest: Science and Technology. Vol 1, Technology Eं Engineering. Wiley-Blackwell, Oxford, https://doi.org/10.1002/9780470751015.

Haour, Georges and Zedtwitz, Max von (2016): Created in China: How China Is Becoming a Global Innovator. Bloomsbury Publishing, London, New York.

IDB (2010): Science, Technology, and Innovation in Latin America and the Caribbean: A Statistical Compendium of Indicators. Inter-American Development Bank, Washington.

Investing in Innovation (2015). Royal Academy of Engineering, September, http://www.raeng.org.uk/publications/reports/investing-in-innovation (accessed 2 December 2017).

Koch, Svea (2015): From Poverty Reduction to Mutual Interests? The Debate on Differentiation in EU Development Policy. Development Policy Review, Vol. 33, No. 4, pp. 479-502, http://dx.doi.org/10.1111/ dpr. 12119.

Kormany.hu (2016): Fokozatváltás a felsôoktatásban. A teljesítményelvú felsôoktatás fejlesztésének irányvonalai [Grade change in higher education. Guidelines in the development of performance-based higher education]. Kormany. hu, EMMI, Budapest.

McLendon, Michael K. (2003): State Governance Reform of Higher Education: Patterns, Trends, and Theories of the Public Policy Process. In: Higher Education: Handbook of Theory and Research, Kluwer, London, pp. 57-143, https://doi.org/10.1007/978-94-010-0137-3_2.

OECD (2011): Fostering Innovation to Address Social Challenges. Workshop Proceedings, OECD, https://www. oecd.org/sti/inno/47861327.pdf (accessed 2 December 2017).

OECD (2012): Innovation for Development: A Discussion of the Issues and an Overview of Work of the OECD Directorate for Science, Technology and Industry. OECD, Paris.

Sener, Sefer and Saridogan, Ercan (2011): The Effects of Science-Technology-Innovation on Competitiveness and Economic Growth. Procedia, Social and Behavioral Sciences, Vol. 24, pp. 815-828, https://doi. org/10.1016/j.sbspro.2011.09.127.

Suha, György and Szatmári, Péter (2015): Felsôoktatási lehetôségek a magyar gazdaságdiplomácia stratégiájában [Higher education opportunities in the strategy of Hungarian economic diplomacy]. Polgári Szemle, Vol. 11, No. 1-3, pp. 265-273.

Tindemans, Peter (2009): Working Document for G77 Ministerial Round Table on Structure. Organization and Funding of Scientific Research, 4th WSF, Budapest. 